\title{
Towards the reaction mechanism of pyrogallol-phloroglucinol transhydroxylase of Pelobacter acidigallici
}

\author{
Wolfram Reichenbecher ${ }^{1}$, Bernhard Schink * \\ Fakultät für Biologie, Universität Konstanz, Postfach 5660, D 78457 Konstanz, Germany
}

Received 1 December 1998; received in revised form 14 December 1998; accepted 7 January 1999

\begin{abstract}
Conversion of pyrogallol to phloroglucinol was studied with the molybdenum enzyme transhydroxylase of the strictly anaerobic fermenting bacterium Pelobacter acidigallici. Transhydroxylation experiments in $\mathrm{H}_{2}{ }^{18} \mathrm{O}$ revealed that none of the hydroxyl groups of phloroglucinol was derived from water, confirming the concept that this enzyme transfers a hydroxyl group from the cosubstrate 1,2,3,5-tetrahydroxybenzene (tetrahydroxybenzene) to the acceptor pyrogallol, and simultaneously regenerates the cosubstrate. This concept requires a reaction which synthesizes the cofactor de novo to maintain a sufficiently high intracellular pool during growth. Some sulfoxides and aromatic $N$-oxides were found to act as hydroxyl donors to convert pyrogallol to tetrahydroxybenzene. Again, water was not the source of the added hydroxyl groups; the oxides reacted as cosubstrates in a transhydroxylation reaction rather than as true oxidants in a net hydroxylation reaction. No oxidizing agent was found that supported a formation of tetrahydroxybenzene via a net hydroxylation of pyrogallol. However, conversion of pyrogallol to phloroglucinol in the absence of tetrahydroxybenzene was achieved if little pyrogallol and a high amount of enzyme preparation was used which had been pre-exposed to air. Obviously, the enzyme was oxidized by air to form sufficient amounts of tetrahydroxybenzene from pyrogallol to start the reaction. A reaction mechanism is proposed which combines an oxidative hydroxylation with a reductive dehydroxylation via the molybdenum cofactor, and allows the transfer of a hydroxyl group between tetrahydroxybenzene and pyrogallol without involvement of water. With this, the transhydroxylase differs basically from all other hydroxylating molybdenum enzymes which all use water as hydroxyl source.
\end{abstract}

Keywords: Anaerobic degradation; Pyrogallol phloroglucinol transhydroxylase; Trihydroxybenzene; Tetrahydroxybenzene; Molybdenum enzyme; (Pelobacter acidigallici)

\section{Introduction}

Trihydroxybenzenes and their carboxylated deriv-

\footnotetext{
Abbreviations: MSTFA, $N$ methyl $N$ trimethylsilyl trifluoro acetamide; tetrahydroxybenzene, 1,2,3,5 tetrahydroxybenzene; SDS, sodium dodecyl sulfate

* Corresponding author. Fax: +49 (7531) 882966;

E mail: bernhard.schink@uni konstanz.de

1 Present address: Department of Biological Sciences, Univer sity of Warwick, Coventry CV4 7AL, UK.
}

atives are degraded anaerobically by the fermenting bacteria Eubacterium oxidoreducens, Pelobacter acidigallici, and Pelobacter massiliensis via the intermediate phloroglucinol, which is subsequently reduced and cleaved hydrolytically [1-3]. Pyrogallol (1,2,3-trihydroxybenzene) and hydroxyhydroquinone $(1,2,4-$ trihydroxybenzene) are converted to the isomer phloroglucinol (1,3,5-trihydroxybenzene) by one or three consecutive transhydroxylation reactions $[4,5]$. The transhydroxylase of $P$. acidigallici catalyzes the 
overall conversion of pyrogallol to phloroglucinol with tetrahydroxybenzene as hydroxyl donor and pyrogallol as hydroxyl acceptor, and tetrahydroxybenzene is regenerated during this reaction. In vivo, the reaction relies on an intracellular pool of about $1 \mathrm{mM}$ tetrahydroxybenzene which has to be replenished with growth [6]. Previous studies reported a formation of tetrahydroxybenzene from pyrogallol in the presence of high concentrations of dimethyl sulfoxide [1] indicating that tetrahydroxybenzene could be synthesized in vivo by a net hydroxylation of pyrogallol $[6,7]$. Similar to other hydroxylating enzymes, the pyrogallol-phloroglucinol transhydroxylase of $P$. acidigallici is a MoFeS protein, and contains iron sulfur centers and molybdopterin guanine dinucleotide as cofactors $[8,9]$.

In the present study, we performed experiments with $\mathrm{H}_{2}{ }^{18} \mathrm{O}$ to check for a possible involvement of water in the hydroxyl transfer reaction. The second part addresses the possibility of a net hydroxylation of pyrogallol.

\section{Materials and methods}

\subsection{Transhydroxylase enzyme preparations}

Pure pyrogallol-phloroglucinol transhydroxylase was prepared as described previously [8]. An enriched enzyme preparation was obtained by passing cell-free extract over a HR 16/10 MonoQ-column (Pharmacia, Freiburg, FRG) and eluting as described [8].

\subsection{Enzyme assays}

Transhydroxylase activity was measured by a discontinuous enzyme assay described before [6]. Pyrogallol $(1 \mathrm{mM})$, tetrahydroxybenzene $(1 \mathrm{mM})$ and the enzyme preparation were added to $50 \mathrm{mM}$ potassium phosphate buffer, $\mathrm{pH} 7.0$, to a final volume of $1 \mathrm{ml}$ in gas-tight $5 \mathrm{ml}$ glass flasks under a nitrogen gas atmosphere. Samples were withdrawn at regular intervals with gas-tight syringes via a butyl rubber seal. The reaction was stopped by adding $\mathrm{H}_{3} \mathrm{PO}_{4}$ to $100 \mathrm{mM}$ final concentration. A net hydroxylation of pyrogallol was assayed with $1 \mathrm{mM}$ pyrogallol and various compounds at the indicated concentrations.

\subsection{Labeling experiment}

The $\mathrm{H}_{2}{ }^{18} \mathrm{O}$ labeling experiment was conducted in a final volume of $0.25 \mathrm{ml}$ with $20 \mathrm{mM}$ phosphate buffer, $\mathrm{pH} 7.0,1 \mathrm{mM}$ pyrogallol, $1 \mathrm{mM}$ tetrahydroxybenzene, $20 \mu \mathrm{g}$ pure transhydroxylase enzyme and $90 \%(\mathrm{v} / \mathrm{v}) \mathrm{H}_{2}{ }^{18} \mathrm{O}$. To stop the reaction, the mixture was acidified as described above. An assay containing only $\mathrm{H}_{2}{ }^{18} \mathrm{O}$, phosphate buffer, and phloroglucinol was treated the same way and served as control.

\subsection{Analysis and preparation of substrates and products}

Usually, 20- $\mu 1$ aliquots of acidified samples were analyzed with an HPLC system (System Gold, Beckman, Munich, Germany) equipped with an autosampler, a reversed-phase column and a scanning variable wavelength detector. Routinely, an UltrasphereODS column (4.6 by $150 \mathrm{~mm}$ ) was run with a varying mixture of $100 \mathrm{mM}$ ammonium phosphate buffer, $\mathrm{pH} 2.6$, and $84 \%(\mathrm{v} / \mathrm{v})$ methanol in $\mathrm{H}_{2} \mathrm{O}$. Aromatic compounds were detected at $260 \mathrm{~nm}$ and quantified using external standards. The sample volume was increased up to $200 \mu \mathrm{l}$ for quantifying compounds at low concentration. For preparative purification of phloroglucinol obtained in the $\mathrm{H}_{2}{ }^{18} \mathrm{O}$ labeling experiment, a larger column $(10 \times 250 \mathrm{~mm})$ was used with $0.05 \mathrm{M}$ ammonium acetate buffer, $\mathrm{pH}$ 3.5. Pooled fractions containing phloroglucinol were subsequently lyophilized.

\subsection{Mass spectrometric analysis of phloroglucinol}

A sample of $5 \mu \mathrm{l}$ of phloroglucinol redissolved in $N, N$-dimethylformamide was mixed with an equal volume of $N$-methyl- $N$-trimethylsilyl trifluoroacetamide (MSTFA) and incubated for silylation at $95^{\circ} \mathrm{C}$ for $1 \mathrm{~h}$. Samples were analyzed by electron ionization with a Finnigan MAT 312 apparatus (Egelsbach, Germany).

\subsection{Chemicals}

Tetrahydroxybenzene was synthesized as described [10] and further purified by reversed-phase chromatography. D- and L-biotin sulfoxide were synthesized according to Melville [11]. The purity of the prepared 
chemicals was verified by HPLC [12]. All other chemicals used were of analytical grade. $\mathrm{H}_{2}{ }^{18} \mathrm{O}$ was purchased from Aldrich, $N$-methyl- $N$-trimethylsilyl trifluoroacetamide from Macherey and Nagel, Düren, Germany.

\section{Results}

\section{1. $\mathrm{H}_{2}{ }^{18} \mathrm{O}$ labeling experiment}

The transhydroxylase reaction was performed in $90 \% \mathrm{H}_{2}{ }^{18} \mathrm{O}$ with pyrogallol as substrate, tetrahydroxybenzene as cosubstrate, and pure transhydroxylase as catalyst. The formed phloroglucinol was purified, derivatized, and analyzed by mass spectrometry. Commercial phloroglucinol treated the same way served as control. All mass spectra contained a group of peaks with masses of 342, 343 and 344, which were due to trisilylated phloroglucinol. The dominant mass of 342 represents phloroglucinol containing only ${ }^{16} \mathrm{O}$ and mainly ${ }^{12} \mathrm{C}$, whereas higher masses were caused by phloroglucinol containing some ${ }^{13} \mathrm{C}$. Phloroglucinol produced from pyrogallol by the transhydroxylase reaction showed the same mass pattern as commercial phloroglucinol (Table 1). No shift towards higher masses was observed, meaning that the phloroglucinol derived from pyrogallol and tetrahydroxybenzene had not incorporated ${ }^{18} \mathrm{O}$ from the labeled water.

\subsection{Pyrogallol oxidation with other oxidizing agents}

Various compounds were tested for their ability to support a net hydroxylation of pyrogallol to tetrahydroxybenzene, either with the enriched enzyme preparation or with pure transhydroxylase enzyme. No reaction was observed within $3 \mathrm{~h}$ if $1 \mathrm{mM}$ pyrogallol was incubated with the following compounds (numbers in brackets give $\mathrm{mM}$ concentrations): $\mathrm{NAD}^{+}$ (5), $\mathrm{NADP}^{+}$(5), FAD (2.5), FMN (2.5), 1,4-benzoquinone (2.5), horse heart cytochrome $c$ (2), methyl viologen (5), cystine ( 1 or 4$)$. If various oxides were incubated with pyrogallol and enzyme, some of the sulfoxides and most of the $N$-oxides tested caused a decrease of the pyrogallol concentration (Table 2). A

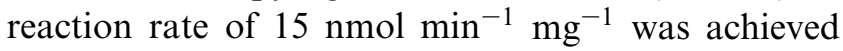
with two aromatic $N$-oxides, pyridine $N$-oxide and 2hydroxypyridine $N$-oxide. Non-aromatic sulfoxides were far less effective; with $10 \mathrm{mM}$ tetramethylene

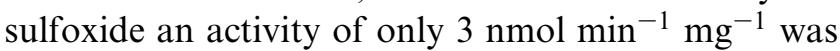
obtained. Also ring substituents influenced the meas-
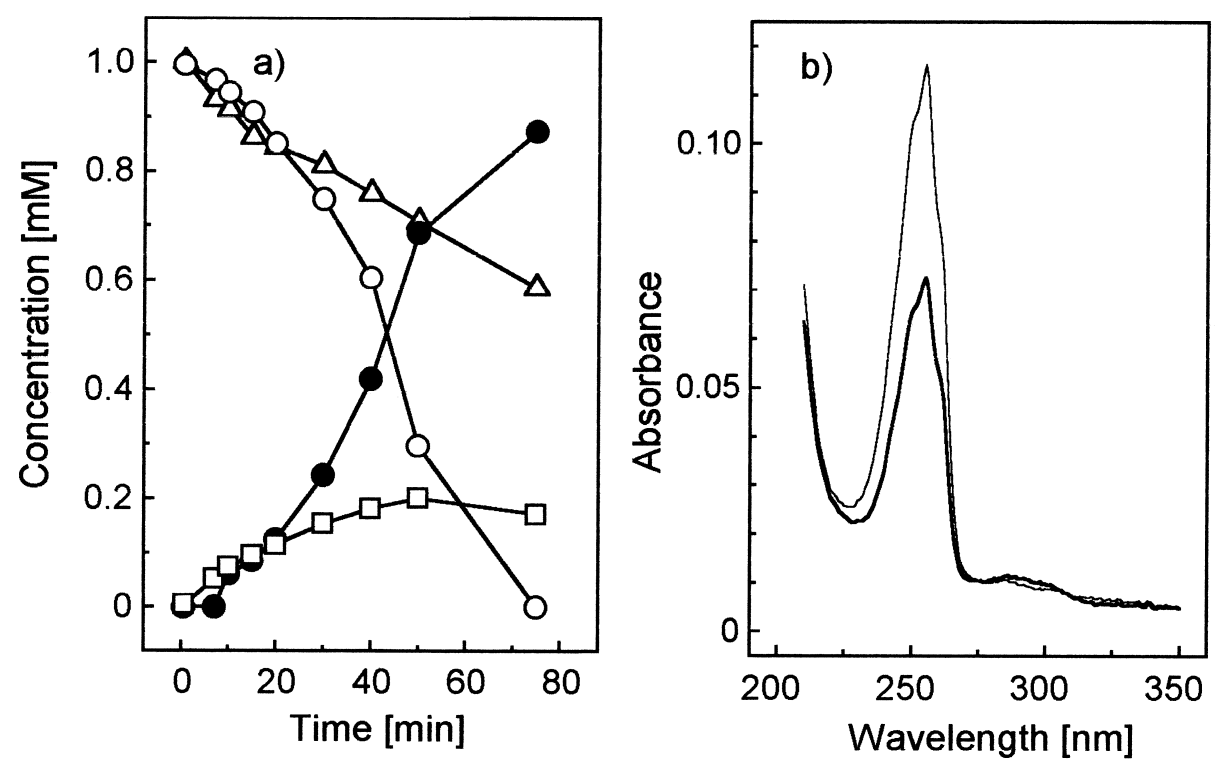

Fig. 1. Reaction of enriched transhydroxylase enzyme preparation with pyrogallol and pyridine $N$ oxide. (a) Time course of the reac tion. $\bigcirc$, pyrogallol; $\Delta, 1 \mathrm{mM}$ pyridine $N$ oxide; $\square$, tetrahydroxybenzene; $\bullet$, phloroglucinol. A new compound appeared corresponding to the decrease of pyridine $N$ oxide (not shown). (b) Absorption spectra of the new compound (thin line) and of authentic pyridine (thick line). 
Table 1

Mass spectra obtained with commercial phloroglucinol (control) and phloroglucinol formed enzymatically from $1 \mathrm{mM}$ pyrogallol in the presence of $1 \mathrm{mM}$ tetrahydroxybenzene, purified transhy droxylase enzyme, and $90 \% \mathrm{H}_{2}{ }^{18} \mathrm{O}$ in two separate experiments (T1 and T2)

\begin{tabular}{llll}
\hline & Peak $(\mathrm{m} / \mathrm{z})$ & Intensity $(\mathrm{V})$ & Proportion $(\%)$ \\
\hline Control & 342 & 3.04 & 68 \\
& 343 & 1.033 & 23 \\
& 344 & 0.4 & 9 \\
& & & \\
T 1 & 342 & 0.16 & 69 \\
& 343 & 0.05 & 23 \\
& 344 & 0.02 & 8 \\
T 2 & 342 & 0.89 & 70 \\
& 343 & 0.22 & 18 \\
& 344 & 0.16 & 12 \\
\hline
\end{tabular}

Phloroglucinol produced was purified by HPLC, lyophilized, de rivatized with $N$ methyl $N$ trimethylsilyl trifluoroacetamide (MSTFA) and then subjected to electron ionization. The table compares the signal intensity of a group of peaks representing trisilylated phloroglucinol, numbers give percentages of contri bution to every mass group of masses 342, 343 and 344 .

urable activity: the activity with 3-hydroxypyridine $\mathrm{N}$-oxide was only $20 \%$ of that with 2 -hydroxypyridine $N$-oxide, and there was no activity with nicotinic acid $N$-oxide, in contrast to nicotinamide $N$-oxide.
Fig. 1 shows the reaction of pyrogallol and pyridine $\mathrm{N}$-oxide in detail. Pyrogallol and pyridine $\mathrm{N}$ oxide were converted to tetrahydroxybenzene and a new compound (not shown in Fig. 1a) which was identified as pyridine on the basis of its retention time in HPLC separation and its absorption spectrum (Fig. 1b). Phloroglucinol was formed if pyrogallol decreased faster than pyridine $N$-oxide. When enriched enzyme preparation was replaced by pure transhydroxylase in an assay with pyrogallol and tetramethylene sulfoxide, tetrahydroxybenzene was still formed, no matter whether 1\% SDS was present or not. Since transhydroxylase is known to be rather insensitive towards SDS [8,9], this observation indicates that both reactions in Fig. 1 were carried out by the transhydroxylase enzyme. When the assay was carried out in the presence of $\mathrm{H}_{2}{ }^{18} \mathrm{O}$, the produced phloroglucinol showed no mass increase over that of the control, indicating that the oxygen required for pyrogallol hydroxylation and subsequent phloroglucinol formation was derived from tetramethylene sulfoxide, not from water. Obviously, the reactions between pyrogallol and the various oxides were again transhydroxylations with the oxides replacing the physiological cosubstrate tetrahydroxybenzene, rather than a net hydroxylation of pyrogallol to tetrahydroxybenzene.

Table 2

Oxides tested as cosubstrates for pyrogallol transformation by enriched transhydroxylase enzyme preparation of Pelobacter acidigallici

\begin{tabular}{|c|c|c|}
\hline & Compound (mM) & Specific activity ( $\mathrm{nmol} \mathrm{min}{ }^{1} \mathrm{mg}$ protein ${ }^{1}$ ) \\
\hline \multirow[t]{8}{*}{ Sulfoxides } & Dimethyl sulfoxide $(1.3 \mathrm{M})$ & 400 \\
\hline & Tetramethylene sulfoxide (10) & 3 \\
\hline & Tetramethylene sulfoxide (100) & 43 \\
\hline & Tetramethylene sulfoxide $(500)$ & 200 \\
\hline & Diphenyl sulfoxide (2 or 10$)$ & 0 \\
\hline & L Biotin sulfoxide (0.6) & 0 \\
\hline & D Biotin sulfoxide (0.6) & 0 \\
\hline & D,L Methionine sulfoxide $(0.2$ or 1$)$ & 0 \\
\hline \multirow[t]{6}{*}{$N$ oxides } & Nicotinamide $N$ oxide (1) & 10 \\
\hline & Pyridine $N$ oxide (1) & 15 \\
\hline & 2 Hydroxypyridine $N$ oxide (1) & 15 \\
\hline & 3 Hydroxypyridine $N$ oxide (1) & 3 \\
\hline & Nicotinic acid $N$ oxide (1) & 0 \\
\hline & Trimethylamine $N$ oxide (1) & 0 \\
\hline
\end{tabular}

Compounds were incubated with $0.1 \mathrm{mg}$ cell free extract and $1 \mathrm{mM}$ pyrogallol for $3 \mathrm{~h}$. 


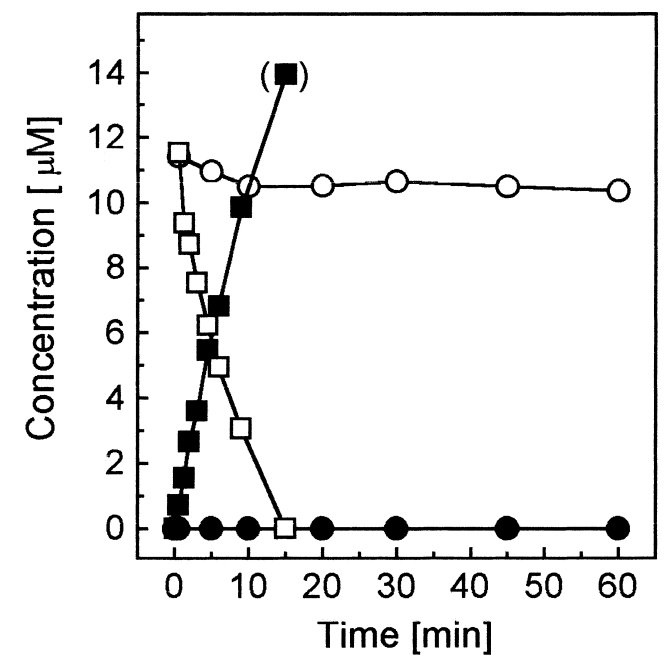

Fig. 2. Conversion of pyrogallol (open symbols) to phlorogluci nol (closed symbols) with $0.53 \mathrm{mg}$ enriched enzyme preparation. Squares, native enzyme; circles, enzyme preheated for $10 \mathrm{~min}$.

\subsection{Transformation of pyrogallol to phloroglucinol in the absence of tetrahydroxybenzene}

If a partially enriched transhydroxylase enzyme fraction was incubated with pyrogallol as sole substrate, no tetrahydroxybenzene or phloroglucinol was formed, confirming earlier observations [6]. If, in similar experiments, the amount of enzyme was drastically increased and the pyrogallol concentration was decreased, a complete conversion of pyrogallol to phloroglucinol could be observed, with no transient formation of tetrahydroxybenzene (Fig. 2). The same was found if a pure transhydroxylase enzyme preparation was used.

In a set of experiments with varying pyrogallol concentrations, pyrogallol was transformed at a significant rate only if provided at concentrations as low as $0.1 \mathrm{mM}$ (Fig. 3a), and the reaction rate depended strictly on the pyrogallol concentration provided (Fig. 3b). At very low concentrations, pyrogallol disappeared remarkably faster than phloroglucinol appeared: $12.5 \mu \mathrm{M}$ pyrogallol decreased at a rate of $2.7 \mathrm{nmol} \mathrm{m^{-1 }} \mathrm{mg}^{-1}$ protein $^{-1}$, compared to $2.3 \mathrm{nmol} \mathrm{min}{ }^{-1} \mathrm{mg}^{-1}$ increase of phloroglucinol. With $5 \mu \mathrm{M}$ pyrogallol, the rates were 7.9

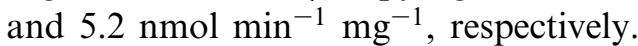

In one experiment, as little as $0.7 \mu \mathrm{M}$ pyrogallol was incubated with $0.13 \mathrm{mg}$ enriched enzyme preparation in a final volume of $0.25 \mathrm{ml}$, and the reaction was stopped at short time intervals (Fig. 4). This was the only experiment in which the formation of free tetrahydroxybenzene was observed. In the first phase, pyrogallol decreased at a rate of $98 \mathrm{nmol}$ $\min ^{-1} \mathrm{mg}$ protein ${ }^{-1}$ without appearance of an equimolar amount of tetrahydroxybenzene or phloroglucinol. Later, the rate dropped to $16 \mathrm{nmol} \mathrm{m^{-1 }}$ $\mathrm{mg} \operatorname{protein}^{-1}$, and tetrahydroxybenzene and phloro-
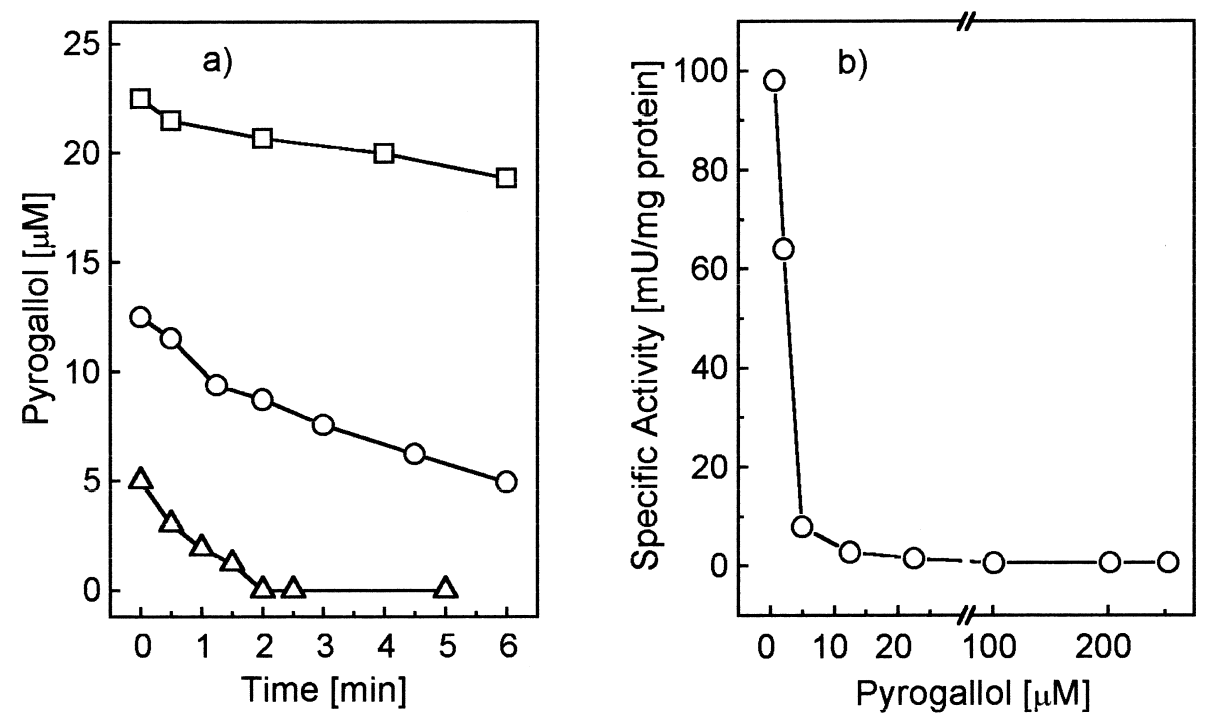

Fig. 3. Pyrogallol transformation at different substrate concentrations. (a) Kinetics of pyrogallol decrease. Each assay contained 0.53 $\mathrm{mg}$ enriched enzyme preparation and different pyrogallol concentrations: $\square, 22.5 \mu \mathrm{M} ; \bigcirc, 12.5 \mu \mathrm{M} ; \Delta, 5 \mu \mathrm{M}$ pyrogallol. (b) Depend ence of pyrogallol transformation rate on the pyrogallol concentration. Most data derived from a and Fig. 4. 


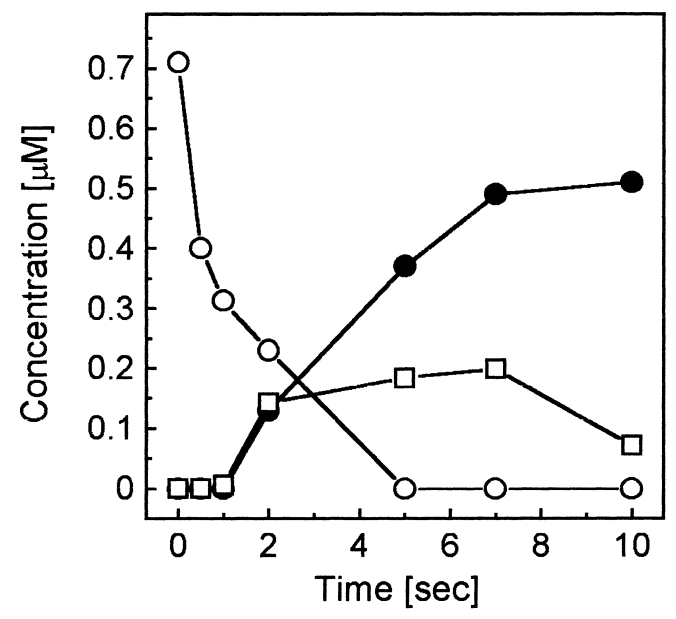

Fig. 4. Kinetics of pyrogallol conversion to phloroglucinol. Each data set was derived from a single experiment containing $0.13 \mathrm{mg}$ enriched enzyme preparation. Data at $0,0.5$, and $1 \mathrm{~s}$ are mean values from three independent measurements. $\bigcirc$, Py rogallol; •, phloroglucinol; $\square$, tetrahydroxybenzene.

glucinol were formed at a similar rate of $20 \mathrm{nmol}$ $\min ^{-1} \mathrm{mg}$ protein ${ }^{-1}$. During the first phase the disappearance of pyrogallol was not balanced by the formation of tetrahydroxybenzene or phloroglucinol.

Since transhydroxylase represents about $10 \%$ of total protein in $P$. acidigallici cell-free extract and assuming that anion exchange chromatography leads to a 2-fold enrichment [8] the amount of transhydroxylase protein in the above-mentioned experiments can be roughly estimated. Table 3 shows that the ratio of substrate molecules over transhydroxylase molecules differed in the experiments by a factor of 8000 . Highest activities were obtained if pyrogallol and transhydroxylase were present at nearly equal concentrations.

\section{Discussion}

In the present study, we showed by an experiment in ${ }^{18} \mathrm{O}$ water that the pyrogallol-phloroglucinol transhydroxylase of $P$. acidigallici transfers hydroxyl substituents only between organic carriers, and there is no exchange with free water. With this, the transhydroxylase differs from all other molybdenum cofactor-containing enzymes which catalyze hydroxylations by oxygen transfer between water and an organic substrate $[13,14]$. These findings support the concept of a transhydroxylation reaction in which a hydroxyl group is transferred from a donor molecule (tetrahydroxybenzene) to an acceptor molecule (pyrogallol) [6]. As part of their concept, the authors postulated an intracellular pool of tetrahydroxybenzene which had to be maintained by an anaplerotic reaction, e.g. an oxidative hydroxylation of pyrogallol, to synthesize the cosubstrate de novo during growth. So far, tetrahydroxybenzene could not be detected in cell extracts of $P$. acidigallici, but it was noted that even an intracellular pool as large as $1 \mathrm{mM}$ would be difficult to detect in cell-free extracts [6].

Net synthesis of tetrahydroxybenzene from pyrogallol would require an oxidant. No commonly used redox mediators, such as pyridine nucleotides or flavin nucleotides, supported formation of tetra-

Table 3

Pyrogallol to transhydroxylase ratios calculated for the assays performed with enriched transhydroxylase enzyme preparation of Pelo bacter acidigallici

\begin{tabular}{ccllll}
\hline $\begin{array}{l}\text { Pyrogallol } \\
\text { concentration }(\mu \mathrm{M})\end{array}$ & $\begin{array}{l}\text { Total pyrogallol } \\
(\mathrm{nmol})\end{array}$ & $\begin{array}{l}\text { Amount of enzyme } \\
\text { preparation }(\mathrm{mg})^{\mathrm{a}}\end{array}$ & $\begin{array}{l}\text { Total } \\
\text { transhydroxylase } \\
\text { protein (nmol) }\end{array}$ & $\begin{array}{l}\text { Specific activity (nmol } \\
\text { min }{ }^{\mathrm{b}} \text { mg protein }^{1} \text { ) }\end{array}$ & $\begin{array}{l}\text { mol Pyrogallol per mol } \\
\text { transhydroxylase }\end{array}$ \\
\hline 1000 & 1000 & 0.08 & 0.12 & 0 & $\sim 8300$ \\
22.5 & 22.5 & 0.53 & 0.8 & 1.5 & $\sim 28$ \\
12.5 & 12.5 & 0.53 & 0.8 & 2.7 & $\sim 17$ \\
5.0 & 5.0 & 0.53 & 0.8 & 6.9 & $\sim 6$ \\
2.1 & 0.53 & 0.13 & 1.0 & 98 & $\sim 0.5$ \\
0.7 & 0.18 & 0.13 & 1.0 & & $\sim 0.2$ \\
\hline
\end{tabular}

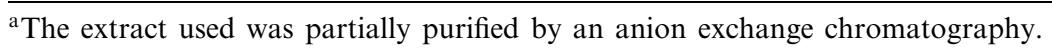

${ }^{\mathrm{b}}$ Assuming that transhydroxylase accounted for $20 \%$ of total protein in this preparation. The molecular mass of the transhydroxylase is $130 \mathrm{kDa}$ according to mass spectrometry. 
Phloroglucinol

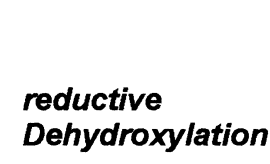

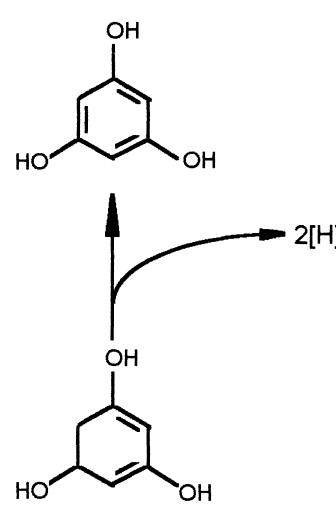

$2[\mathrm{H}] \longrightarrow$

1,2,3,5-Tetrahydroxybenzene<smiles>C=CC1CC(=O)CC(=O)C1=O</smiles><smiles>C=CC1CC(=O)CC(O)C1=O</smiles>
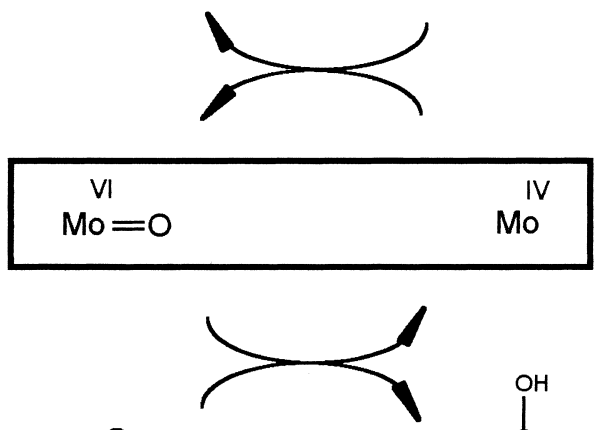<smiles>O=C1C=CC=C(O)C1=O</smiles><smiles>O=C1C=C(O)C=C(O)C1=O</smiles><smiles>O=C1C=C(O)C(=O)C(O)=C1</smiles><smiles>CCC1CC1C</smiles><smiles>CC(C)O</smiles><smiles>Oc1cc(O)c(O)c(O)c1</smiles><smiles>O=C1CC(=O)C(O)C(=O)C1</smiles>

\section{1,2,3,5-Tetrahydroxybenzene}

Fig. 5. Proposed model for the reaction mechanism of pyrogallol phloroglucinol transhydroxylase of Pelobacter acidigallici.

hydroxybenzene from pyrogallol. Instead, we found that some sulfoxides and $N$-oxides could be used as oxidants, confirming earlier studies with dimethyl sulfoxide [6,7]. However, these oxides acted as alternative cosubstrates in transhydroxylation reactions rather than as net oxidizing agents. Sulfoxides and $N$-oxides are substrates for two classes of molybdenum cofactor-containing reductases [15]. Dimethyl sulfoxide reductase of Escherichia coli reacts with pyridine $\mathrm{N}$-oxides substituted at the 2-position at the same rate as the non-substituted compound, whereas a hydroxyl group at the 3-position decreased the reaction rate substantially [16]. Our transhydroxylase behaved similarly: with pyridine $N$-oxide and 2-hydroxypyridine $N$-oxide the pyrogallol conversion rate was the same, but it was five times lower with 3-hydroxypyridine $\mathrm{N}$-oxide. Since pyridine $\mathrm{N}$-oxides acted as cosubstrates in the transhydroxylation reaction in a similar way as tetrahydroxybenzene, the impeding effect of a hydroxyl group in meta 
position to the transferred group becomes understandable.

Pyrogallol could be converted to phloroglucinol in the absence of added tetrahydroxybenzene if very little pyrogallol and high amounts of enzyme were applied. This effect was never observed in previous experiments in which, typically, $1 \mathrm{mM}$ pyrogallol and $0.1 \mathrm{mg}$ cell-free extract were used [6]. The cell-free extract used in those studies was prepared anoxically, whereas the enzyme used in the present study was prepared under air. Obviously, oxygen oxidized the enzyme in a way to allow an oxidative hydroxylation of pyrogallol to tetrahydroxybenzene and subsequent transhydroxylation to phloroglucinol. Transient accumulation of tetrahydroxybenzene was observed only in the experiment with the highest reaction activity. For the other experiments, intermediate tetrahydroxybenzene formation can be deduced indirectly from the fact that initially pyrogallol decreased faster than phloroglucinol was formed. Obviously, in these cases, tetrahydroxybenzene reacted further to phloroglucinol, perhaps even without being released from the enzyme.

The rate of pyrogallol conversion depended drastically on the substrate concentration. At e.g. $22.5 \mu \mathrm{M}$ pyrogallol, the rate was $1.5 \mathrm{mU} \mathrm{mg}^{-1}$ and reached a maximum of $98 \mathrm{mU} \mathrm{mg}^{-1}$ at 2.1 to $0.7 \mu \mathrm{M}$ pyrogallol when the ratio of substrate to enzyme molecules was about 1 . This drastic influence of the pyrogallol concentration may be explained by an extreme form of substrate inhibition: enhanced substrate concentrations may impede binding of the structurally related cosubstrate tetrahydroxybenzene, either at the same or at a separate binding site. Substrate inhibition had been also found in earlier studies; the activity was maximal if pyrogallol and tetrahydroxybenzene were present at about equal concentrations [6]. This is also reflected in the similar $K_{\mathrm{m}}$ values for pyrogallol $(0.75 \mathrm{mM})$ and tetrahydroxybenzene $(0.80 \mathrm{mM})$ [8].

On the basis of our present and former results, we propose a model for the conversion of pyrogallol to phloroglucinol by the transhydroxylase enzyme in which the oxidative hydroxylation of pyrogallol is combined with the reductive dehydroxylation of tetrahydroxybenzene via the molybdenum cofactor (Fig. 5). Both reactions are equivalent to the oxidative half-cycle and the reductive half-cycle known of other molybdenum cofactor-containing enzymes [14]. In contrast to those, oxygen is not derived or incorporated from water, but transferred between two aromatic compounds. According to our model, oxidation and hydroxylation of pyrogallol are two subsequent steps. In other molybdenum-cofactorcontaining enzymes, both steps are assumed to take place simultaneously or subsequently, depending on the reaction mechanism [14].

Simultaneous with the hydroxyl group transfer, redox reactions are required in both the substrate and the cosubstrate molecules to facilitate oxidative hydroxylation and reductive dehydroxylation by forming dioxo derivatives that are stabilized by tautomerization to various resonance structures (Fig. 5). In these redox reactions, the iron sulfur clusters of the transhydroxylase enzyme [9] could be involved. The transhydroxylase reaction does not require external redox carriers in vitro.

Although we used an oxo group in our model, the species of the transferred oxygen is unknown. Oxotransferases of the dimethyl sulfoxide reductase family transfer an oxo group; the hydroxylases in the xanthine oxidase family transfer a water ligand to the substrate, and a hydride back from the substrate to the cofactor [17]. Involvement of a hydride transfer has not been investigated in this study. Members of the xanthine oxidase family carry cyanide-labile sulfur as common molybdenum ligand. Cyanide is not a potent inhibitor for our transhydroxylase [8], and it may not belong to this group, therefore. However, it does not group with other molybdenum enzymes either $[9,12]$.

The question remains to be answered how the cofactor is formed and maintained in the growing cell culture. The strictly fermenting bacterium $P$. acidigallici has to balance a net synthesis of tetrahydroxybenzene from pyrogallol by formation and release of a reduced product, e.g. a dihydroxybenzene, such as resorcinol. Dihydroxybenzenes were never observed in cultures of Pelobacter acidigallici. A rough estimate assuming a growth yield of $10 \mathrm{~g} \mathrm{~mol}^{-1}$ [2], a dry matter content of cells of $25 \%$, and an intracellular tetrahydroxybenzene concentration of $1 \mathrm{mM}$ as required for maximal substrate turnover [6] allows to calculate the resorcinol concentration in the growth medium expected from tetrahydroxybenzene formation to be $0.4 \mu \mathrm{M}$. From the results of the pres- 
ent study, it turns out that the intracellular tetrahydroxybenzene concentration could even be substantially lower, provided that it is in the same order of magnitude as the intracellular pyrogallol concentration, to secure sufficient substrate turnover activity. Actually, only the transhydroxylase enzyme itself needs to be maintained in an oxidized state as our experiments with oxidized enzyme preparations indicated; this would correspond to a concentration of reduced coproduct in the growth medium as low as $40 \mathrm{nM}$ after turnover of $10 \mathrm{mM}$ pyrogallol (assuming that transhydroxylase makes up $10 \%$ of the cell protein; [8]), substantially lower than we could ever detect it. From our experiments, we cannot deduce the identity of this coproduct; it may even be associated with the cell material, and would thus be very hard to detect.

\section{Acknowledgements}

We would like to thank Klaus Hägele for performing the mass spectrometric analysis of phloroglucinol and Andreas Kappler for helpful suggestions concerning the chemistry of the transhydroxylase reaction and for synthesizing tetrahydroxybenzene and biotin sulfoxide. Fruitful discussions with Drs. Peter Kroneck and Janos Rétey are gratefully acknowledged.

\section{References}

[1] L.R. Krumholz, M.P. Bryant, J. Bacteriol. 170 (1988) 2472 2479.

[2] B. Schink, N. Pfennig, Arch. Microbiol. 133 (1982) 195201.

[3] S. Schnell, A. Brune, B. Schink, Arch. Microbiol. 155 (1991) 511518.

[4] A. Brune, B. Schink, Arch. Microbiol. 157 (1992) 417424.

[5] A. Brune, S. Schnell, B. Schink, Appl. Environ. Microbiol. 58 (1992) 18611868.

[6] A. Brune, B. Schink, J. Bacteriol. 172 (1990) 10701076.

[7] J.D. Haddock, J.G. Ferry, J. Bacteriol. 175 (1993) 669673.

[8] W. Reichenbecher, A. Brune, B. Schink, Biochim. Biophys. Acta 1204 (1994) 217224.

[9] W. Reichenbecher, A. Ruediger, P.M.H. Kroneck, B. Schink, Eur. J. Biochem. 237 (1996) 406413.

[10] R.A. Baxter, J.P. Brown, Chem. Ind. 27 (1967) 1171.

[11] D.B. Melville, J. Biol. Chem. 208 (1954) 495501.

[12] D.M. Bowers Komro, J.L. Chastain, D.B. McCormick, Methods Enzymol. 122 (1986) 6367.

[13] B.E. Schultz, R. Hille, R.H. Holm, J. Am. Chem. Soc. 117 (1995) 827828.

[14] C. Kisker, H. Schindelin, D.C. Rees, Annu. Rev. Biochem. 66 (1997) 233267.

[15] C. Iobbi Nivol, J. Pommier, J. Simala Grant, V. Mejean, G. Giordano, Biochim. Biophys. Acta 1294 (1996) 7782.

[16] J.L. Simala Grant, J.H. Weiner, Microbiology 142 (1996) 32313239

[17] R. Huber, P. Hof, R.O. Duarte, J.J.G. Moura, I. Moura, M. Y. Liu, J. LeGall, R. Hille, M. Archer, M.J. Romao, Proc. Natl. Acad. Sci. USA 93 (1996) 88468851. 